\title{
Algo más sobre escultura sevillana en Canarias. Nuevas piezas atribuidas a Blas Molner (1738-1812)
}

\author{
Juan Alejandro Lorenzo Lima \\ Universidad Europea de Canarias \\ juanalejandro.Iorenzo@universidadeuropea.es
}

RESUMEN: Este artículo procura el estudio de varias esculturas que pueden atribuirse a Blas Molner (1738-1812) en Canarias, así como una contextualización de otras que ya eran conocidas y el artista firmó antes de 1771. Se plantea un análisis en clave contextual, resaltando su singularidad con un punto de vista histórico, artístico y comercial.

PALABRAS CLAVE: Escultura; Comercio artístico; Blas Molner; Sevilla; Islas Canarias; Arte del siglo XVIII; Arte español.

\section{Something more about Sevillian Sculptures in the Canary Islands. New Works Attributed to Blas Molner (1738-1812)}

ABSTRACT: This essay provides a study of some sculptures that can be attributed to Blas Molner (1737-1812) in the Canary Islands and others that were already known, signed by the artist before 1771. It proposes a contextual analysis, focusing on its value with a historical, artistic and commercial approach.

KEYWORDS: Sculpture; Artistic Trade; Blas Molner; Seville; Canary Islands; $18^{\text {th }}$ Century Art; Spanish Art.

Recibido: 15 de noviembre de 2017 / Aceptado: 10 de mayo de 2018.

Recientemente, al investigar sobre esculturas importadas a Canarias cuando concluía el Antiguo Régimen, reparábamos en piezas sevillanas que merecen una atención mayor por su representatividad variable en lo artístico y lo histórico. Las conclusiones ofrecidas en un estudio anterior nos ayudaron a vislumbrar el contexto en que se produjo el encargo de todas ellas (Lorenzo Lima, 2018: 1-57), aunque no la valía que adquieren por atenerse a una misma realidad piadosa, creativa y mercantil. Respalda ese hecho la coyuntura surgida en torno a las propias obras con un carácter concreto, porque, a diferencia de lo sucedido antes, las últimas décadas del siglo XVIII no eran un tiempo favorable para el encargo de efigies gaditanas o sevillanas. En ello repercutieron el trabajo que acometía entonces José Luján Pérez (1756-1815), imaginero grancanario que asimiló en sus creaciones las directrices del gusto moderno, y la receptividad de los comitentes isleños a otros mercados de alcance internacional como Madrid, Génova y algunas ciudades de América, ya que hasta ese momento no se había diversificado tanto la adquisición de manufacturas artísticas para el medio local (AA. W., 2007).

De acuerdo a ese panorama, el Setecientos es un periodo clave a la hora de comprender la evolución de las artes en el Archipiélago y su vínculo con centros foráneos, pues lo sucedido entonces trajo consigo fundamentos o principios de acción que alteraron la dinámica heredada. No debe obviarse que desde el siglo XV Sevilla fue un referente para todo tipo de importaciones y a la entonces "ciudad principal», ya sea de un modo o de otro, los canarios acudieron para satisfacer la demanda reiterada de tallas, bordados, tejidos con los que vestirse a la moda, ornamentos de seda, metales, en menor medida pinturas, cerámica, menaje doméstico y toda clase de enseres que requería el culto divino. Al contrario de lo que se manifestaba habitualmente, la dinámica comercial de esa centuria posibilitó la importación continua de productos andaluces

Cómo citar este artículo: LORENZO LIMA, Juan Alejandro, «Algo más sobre escultura sevillana en Canarias. Nuevas piezas atribuidas a Blas Molner (1738-1812)", Boletín de Arte-UMA, n. ${ }^{\circ}$ 39, Departamento de Historia del Arte, Universidad de Málaga, 2018, pp. 169-181, ISSN: 0211-8483, DOI: http://dx.doi.org/10.24310/BoLArte.2018. v0i39.4864 
y, aunque no son tan numerosas ni variadas, durante el XVIII proliferaría también el envío de esculturas por causas muy diversas (Concepción Rodríguez, 1995). Después de 1752 el imaginero preferido de la clientela local fue Benito de Hita y Castillo (1714-1784), cuya producción existente en Canarias, cada vez mejor conocida y documentada, describe un panorama válido a la hora de entender el fenómeno importador (Pérez Morera, 2015: 88-107); y a la centuria siguiente corresponden algunas obras que pueden atribuirse a Domenico Giscardi (1725-1805) y a Juan de Astorga (1777-1849), pues el último, tal vez a quien varias cartas refieren como «único escultor de crédito», fue tanteado para ejecutar un Cristo que la nueva catedral de La Laguna necesitaba después de 1819 (Lorenzo Lima, 2016: 401-431).

En el panorama cambiante que describen las décadas finales del Setecientos se enmarcan piezas estimables, al subsistir en las Islas efigies de madera que alcanzan notoriedad por lo vistoso de sus estofados y carnaciones, otras que copian los modelos de autores previos sin mayor originalidad y excepcionalmente algunas de terracota policromada que, como el San Miguel Arcángel de San Sebastián de La Gomera, guardan relación con el arte de Cristóbal Ramos (1725-1799) (Lorenzo Lima, 2018: 19-20). El ajuste, la ejecución y el envío posterior de dichas obras se produjeron al tiempo en que Hita seguía trabajando para los comitentes locales, puesto que el envío de esculturas suyas a Canarias está documentado hasta 1784, el mismo año de su muerte (Herrera García, 2009: 178-179). Para esas fechas Blas Molner (1738-1812) ya era popular en el medio hispalense y, como autor de referencia por trabajos acometidos en la propia ciudad o por su vínculo con la Real Escuela de las Tres Nobles Artes, no permaneció al margen de quienes gestionaban desde Cádiz y Sevilla encargos que tenían como destino final los puertos del Archipiélago. Por eso mismo es factible la identificación de Molner con el artífice que comerciantes de la familia Gough eligieron para afrontar la hechura de una Inmaculada en 1788, siendo aludido entonces como «el mejor (...) que aquí [entiéndase Sevilla] se conoce» (Archivo Histórico Provincial de Santa Cruz de Tenerife (AHPT): Archivo Zárate Cólogan (AZC). Correspondencia. Sign. 942/06).

Ese prestigio local -y por añadidura el reconocimiento de un maestro foráneo en clara progresión, que remitía sus creaciones más allá del ámbito sur-peninsular- queda avalado en Canarias por tres obras firmadas en la peana, pues en una de ellas puede leerse con facilidad: EN SEVILLA D. BLAS MOLNER / NATURAL DE VALENCIA. Se trata de imágenes que desde 1771 presidieron la ermita de El Ancón, un paraje costero de La Orotava donde seguían conservándose al tiempo de su publicación (Acosta Jordán, 2004: 9-20). A este hallazgo se sumó luego una propuesta convincente de atribución para la titular del templo matriz de la isla de La Gomera (Amador Marrero y Rodríguez Morales, 2007: 240) y el recuerdo a una hipotética autoría sobre la Inmaculada que preside la parroquia de Valverde en El Hierro, sugerida años atrás por algunos investigadores (Fraga González, 1998: 189-195) y avalada en mayor medida por la documentación epistolar que permite su estudio (Lorenzo Lima, 2018: 31-32). En este artículo defendemos la posibilidad de que Molner esculpiera al menos tres efigies más que conserva la iglesia de la Concepción de La Orotava, aunque sólo dos de ellas guardan relación con el amueblamiento de su fábrica antes de ser bendecida en 1788 (AA V: 2003).

\section{Blas Molner. En Sevilla, natural de Valencia}

La notoriedad que Blas Molner alcanzó en el medio hispalense no resulta comparable con el bagaje historiográfico ni con lo que sabemos fehacientemente de su trayectoria, porque hasta el momento es uno de los pocos escultores que trabajaron con éxito en Sevilla y no dispone de una monografía o publicación propia. Últimos estudios han suplido esa carencia: esencialmente los trabajos compiladores de Escudero Marchante (2009a: 125-129), (2009b: 201-205) y (2006c: 307-316) (con bibliografía previa que no desarrollamos por la exposición circunstanciada que hizo dicho autor), pero, al margen de los avances procurados en diverso tiempo, se echa en falta una investigación que contextualice mejor sus contribuciones a la imaginería levantina y andaluza durante las últimas décadas del Antiguo Régimen. No debe obviarse que ese periodo coincide con un tiempo de decadencia para la escuela sevillana y la aproximación de muchos maestros a discursos teóricos en vigor (Herrera García, 2014: 269293), aunque ni su labor ni la de otros coetáneos de Andalucía obtuvo el respaldo que ellos mismos, los intelectuales cercanos y sus patrocinadores anhelaban en el seno de la 
Real Academia de Bellas Artes de San Fernando (Recio Mir, 2007: 133-156).

Dicha coyuntura contrasta con el reconocimiento que Molner ganó pronto en la ciudad de Sevilla, donde vivía ya en 1766. Atrás quedaron los años de formación en Valencia junto al maestro Tomás Llorens (1713-1772) y quizá en el seno de la efímera Academia de Santa Bárbara, de modo que ese bagaje y su origen levantino, tan apreciado en aquel tiempo, alentaron una estima de la que se hizo acreedor con inmediatez. Los años siguientes vienen marcados por su vínculo con intelectuales y eruditos ilustrados que residieron en la localidad como Melchor Gaspar de Jovellanos (1744-1811), el II conde del Águila Miguel de Espinosa (1715-1784), Juan Bautista Muñoz (1745-1799) o Francisco de Bruna (1719-1807), entre otros, por lo que no extraña su participación en el establecimiento de la Real Escuela de las Tres Nobles Artes (1775). En ella y en centros educativos afines desplegó una meritoria actividad docente hasta que la muerte le sobrevino en enero de 1812, algo que se tradujo antes en diversas distinciones y en labores acordes a los cargos que detentó en dichas entidades (Escudero Marchante, 2009a y 2009b).

Esta dimensión pública del maestro ha ensombrecido su labor cotidiana como imaginero y retablista de gusto moderno, aunque de lo último se han publicado ya varios estudios que confirman su animadversión hacia el quehacer de oficiales sin especialización o desfasados en lo estético (fundamentalmente Recio Mir, 2000a: 41-50 y 2000b: 129147). No en vano, como artista culto e instruido, dotó a sus creaciones de mayor trasfondo y carga conceptual, sin contradecir los convencionalismos en que venía desenvolviéndose la imaginería tradicional en Sevilla al amparo de maestros influyentes como Cayetano de Acosta (1709-1778) o los ya citados Cristóbal Ramos y Benito de Hita y Castillo (Roda Peña, 2014). De ahí que ejecutase algunas obras civiles, imaginería de distinto tamaño que decora retablos de gusto tardobarroco o neoclásico, esculturas concebidas para la importación y, muy especialmente, simulacros procesionales que perpetúan modismos barroquizantes en un contexto proclive a su reinvención estética y funcional (Ros González, 2009: 307-316). Tal coyuntura explica que la producción de este maestro, poco conocida todavía y muy desigual, no se circunscriba a los templos de la ciudad de Sevilla y su entorno, porque buena parte de ella se emplaza lejos del lugar donde vivió, casó con una sobrina política del arquitecto Lucas Cintora (1732-1800) y tuvo al menos un hijo, enseñó los principios del arte, emprendió negocios mercantiles y, sobre todo, reivindicó la valía del «oficio de escultor» durante décadas (Ros González, 1999).

Paradójicamente, esa circunstancia no ha repercutido en un reconocimiento mayor de su obra ni incita al análisis de un amplio grupo de comitentes que incluye nobles, canónigos, clérigos de diverso estatus, gremios, comunidades de frailes y monjas, burgueses, ricos comerciantes, organismos civiles, cofradías y cabildos municipales (Escudero Sánchez, 2009b: 204-205). Ello justifica también que, al margen de la ciudad, trabajos suyos fueran destinados a pueblos de la periferia sevillana (Carmona, Écija, Aznalcóllar, Utrera, Morón de la Frontera, Lebrija y Valencina) y a otros de las provincias de Huelva (Ayamonte, Valverde del Camino, Zalamea la Real y Manzanilla), Cádiz (Sanlúcar de Barrameda), Córdoba (Lucena y Aguilar de la Frontera), Badajoz (Zahinos, Montijo, Aceuchal y Zafra), Navarra (Echalar) y Santa Cruz de Tenerife (Valverde, San Sebastián de La Gomera y La Orotava).

De los últimos nos ocuparemos en los epígrafes siguientes, pero antes de ello conviene advertir que tal dinámica no resulta novedosa para la época ni para el entorno del artista. Antecesores suyos hicieron lo mismo con regularidad (Rodríguez Morales, 2010: 457-472) y, de acuerdo a lo estipulado en documentos notariales, sabemos que la aventura comercial fue común para Molner y su familia por circunstancias diversas. Durante la década de 1790 el maestro invirtió parte de sus ganancias en la compra de géneros y ropa nueva que toda clase de apoderados vendían en la ciudad de Lima (Perú), por lo que tales negocios le obligaron a tratar con comerciantes de origen europeo y a comparecer ante el escribano para firmar regularmente las escrituras que necesitaba (Ros González, 1999: 515532). Antes de esas transacciones ya se había aventurado con su arte en el comercio atlántico y, como antesala de lo sucedido en el Nuevo Mundo, el envío de esculturas hasta Tenerife forma parte del mismo entramado mercantil. El Archipiélago era un lugar idóneo a la hora de obtener rentabilidad e incentivar la producción local durante un periodo complejo, convirtiéndose en una alternativa laboral para aquellos imagineros que inauguraron la contemporaneidad y ampliaron de ese modo sus horizontes profesionales (Lorenzo Lima, 2018: 7-11). 


\section{Imágenes para la ermita de El Ancón}

La producción de Blas Molner cuenta en Canarias con testimonios ineludibles, al existir al menos tres obras firmadas que no se conservan ya en su emplazamiento originario (Acosta Jordán, 2004: 9-20). Responden a una petición que el artista atendió entre 1767 y 1771, por lo que, de acuerdo a esa cronología, podrían estimarse como uno de los primeros trabajos que afrontó para la exportación en su obrador y domicilio de la Alameda². Las imágenes no tienen igual formato y representan a San José con el Niño, San Juan Nepomuceno y la Virgen de Montenegro, la última una iconografía inusual entre los escultores sevillanos del Barroco [1].

Las tres son consecuencia de un encargo formulado por el escribano José de Montenegro, a quien se debe la fundación del inmueble donde recibieron culto desde el mismo tiempo de su llegada a la isla en torno a 1770. De esa modesta edificación y de la activa labor de patrocinio que desarrolló dicho comitente se han ocupado con anterioridad otros investigadores (Rodríguez Bravo, 2015: 199-241, con bibliografía precedente), de modo que remitimos a lo ya publicado sobre el tema. Sin embargo, conviene resaltar algunos aspectos para advertir la valía de un encargo tan revelador y su repercusión piadosa, notable tras la apertura del templo en 1771. Montenegro refirió a menudo la devoción que sentía hacia "esta Virgen (...) aparecida en Liorna» y, aunque no lo explica como tal, una determinación así esconde el anhelo de significar piadosamente el apellido que dio sentido a un linaje reivindicado con iniciativas muy diversas en el medio local (Luque Hernández, 2004: 241-254). Ello justifica también la elección de sus devociones principales, porque, si la Virgen de Montenegro o Montenero resultó clave en esa circunstancia, San José era invocado como "santo patrón» y San Juan Nepomuceno fue tenido como protector de la familia, ya que en 1736, siete años después de su canonización en Roma, el mismo José colocó en la parroquia de la Concepción un «retablito» y el cuadro o la lámina procesional de dicho santo ${ }^{3}$.

No extraña, pues, que en 1767 obtuviese licencia para construir la ermita de El Ancón inmediata a las casas de su hacienda e impusiera en ella la celebración de una misa todos los domingos y días de fiesta, a la que podían acudir los vecinos y jornaleros de la zona, pobres y mal vestidos, junto a otros parientes que residían en el litoral durante los meses de verano ${ }^{4}$. Concretó también la parafernalia cultual de dichas efigies, cuya fiesta principal debía celebrarse coincidiendo con la onomástica de Santa Ana. Para ese fin dotó adecuadamente el recinto e incluso encargó un retrato suyo que acabaría colgando en el presbiterio, reconocido por los visitadores del obispo Martínez de la Plaza en $1789^{5}$ e inventariado allí en $1905^{6}$.

Obviando que este lienzo y la decoración de su retablo podrían atribuirse al pintor local Cristóbal Afonso (1742-1797), las obras de mayor entidad que tuvo la ermita corresponden con las efigies de Molner. De su autoría no cabe duda por la firma ya citada que cada una de ellas ostenta al pie ${ }^{7}$, pero se desconoce lo relativo al encargo, los pagos que recibió el imaginero y las circunstancias del envío posterior hasta Tenerife. No obstante, es probable que su hechura fuera ajustada después de 1767 por un sobrino del fundador: el luego beneficiado de la parroquia matriz Juan Nepomuceno de Montenegro y Ocampo, quien estudiaba entonces en Sevilla y forjó una reputación notable (Rodríguez Bravo, 2015: 212). Si no fuera así, cabría especular en una mediación de agentes de la compañía comercial Juan Cólogan e Hijos, a quienes Montenegro refiere en el testamento de 1789 por la venta del vino que producía en sus propiedades del campo ${ }^{8}$. Además, entre al menos 1754 y 1788 intercambió con los titulares de dicho establecimiento varias cartas donde trataba asuntos relativos al comercio menor, habitualmente con un carácter interinsular?.

Las imágenes de Blas Molner son piezas atractivas y un aval para formular otras atribuciones en Canarias. La configuración de sus peanas, por ejemplo, puede ponerse en relación con efigies de San Francisco de Borja y San Juan Nepomuceno que la parroquia de la Concepción conserva desde al menos 1776 [5] y [6], pero, al margen de ello, estos trabajos sirven para calibrar los modelos que recurrió entonces su autor. Las figuraciones de San José y San Juan Nepomuceno reproducen tipos roldanescos que Pedro Duque Cornejo (1678-1757) mantuvo en vigor hasta bien entrado el Setecientos, aunque el sentido interpretativo de Molner no obvia el aplomo dieciochesco ni sus fórmulas variables de representación, siempre con policromías cuidadas y recursos comunes a la hora de simular tejidos contemporáneos con estofados al temple, pocos añadidos a punta de pincel y rocallas de estuco relevadas al borde de la muceta, el hábito clerical, los galones inferiores de la túnica y el manto sobrepuesto del mismo San José que calza sandalias distin- 

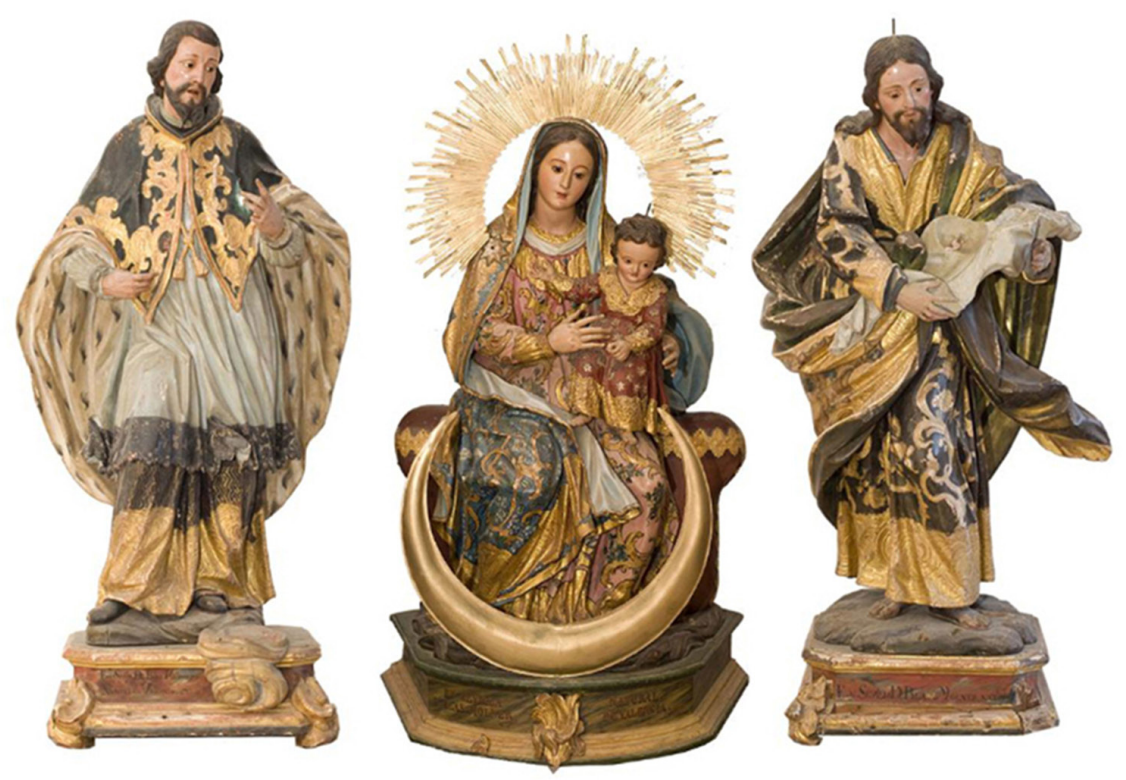

1. Blas Molner, San Juan Nepomuceno. Virgen de Montenegro. San José. Colección particular, Tenerife (foto: Juan Alejandro Lorenzo)

tivas sobre una base de simulación rocosa, común en otras creaciones del artista (Roda Peña, 1993: 369-378). Pese a ello, el aspecto de ambas cambiaría en algunos detalles con el paso del tiempo. En 1930 Nicolás Perdigón (1853-1939) arregló los deterioros del crucifijo de San Juan Nepomuceno y encarnó de nuevo la imagen del Niño Jesús ${ }^{10}$, lo que vendría a explicar cierta afinidad de esa pequeña talla con sus policromías sin matices ni veladuras, elaboradas ya con pigmentos industriales.

Más complejo resulta el análisis de la titular. En julio de 1883 la Virgen fue intervenida por el mismo Perdigón, quien anotaba en su diario que le practicó entonces una «reforma general» y como tal lo hizo constar en un diploma o credencial que colgaba en la ermita ${ }^{11}$. Un análisis somero de la obra demuestra que dicho artista modificó los rasgos fisonómicos, le puso añadidos como el sol y la luna de metal sobredorado, colocó un corazón al Niño, repintó parte del atuendo, retiró motivos de talla en el basamento y quizá marmoleó la peana sobrescribiendo una inscripción con el nombre del autor, pero no ocultaría la belleza de los repertorios de gusto rococó que vislumbran la túnica y el manto sobrepuesto con motivos en estuco relevado para las cenefas del borde, res- tos de estofado y aplicaciones florales de vistoso tratamiento a punta de pincel.

A pesar de dichas alteraciones, en la obra sigue distinguiéndose el simulacro o icono medieval que inspiró al artista (Acosta Jordán, 2004: 15-16). La imagen reproduce en lo esencial a la Madonna delle Grazie o di Montenero que se atribuye al pintor Jacopo di Miquelle detto Gera (...1341-1395...), muy popular en Toscana, cuyo santuario en las proximidades de Livorno empezaría a reconstruirse desde 1744 y despertó pronto el interés de viajeros, eruditos y devotos que lo frecuentaron para conocer la historia de su aparición milagrosa a unos pastores del lugar en mayo de 1345 (Cecchi Toncelli, 2001). No descartamos la posibilidad de que Montenegro fuera partícipe de la difusión que tuvo su culto gracias a publicaciones dieciochescas como la de Giorgio Oberhausen, editada en Lucca durante 1745 e ilustrada con una lámina que, a modo de vera efigie, reproduce el cuadro que Molner copiaría en su talla (Oberhausen, 1745) [2]. Distintivas de esta iconografía mariana son la estrella al hombro, la actitud sedente, los gestos inconfundibles del Niño y el pequeño pájaro que se posaba sobre el brazo izquierdo de la Virgen, ya perdido. 


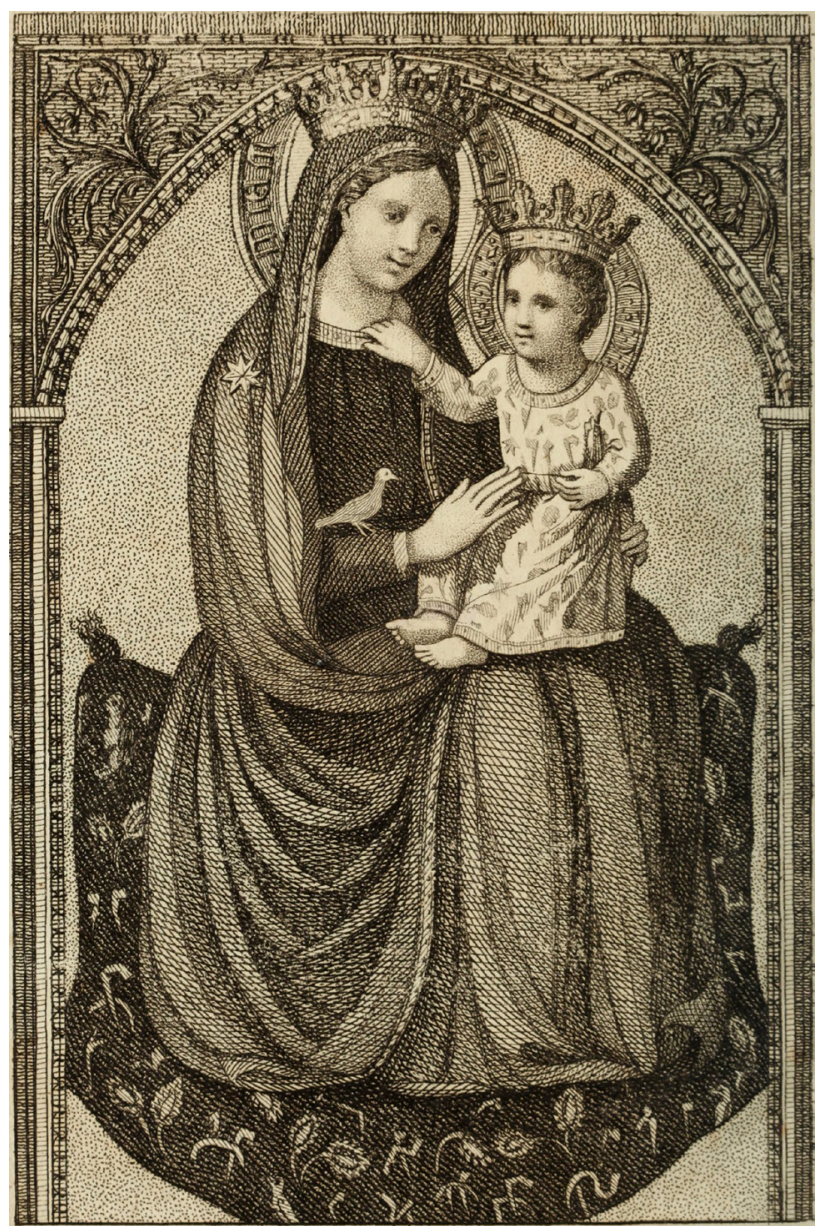

2. Estampa devocional de la Virgen de Montenegro (impreso de Oberhausen, 1745). Colección particular, Madrid (foto: Juan Alejandro Lorenzo)

\section{Una nueva talla de San Juan Nepomuceno}

El auge de ciertas devociones favoreció la proliferación de efigies suyas en templos, oratorios y espacios domésticos, siendo ello un indicio clave para calibrar la complejidad del hecho piadoso y de sus múltiples manifestaciones artísticas. En este sentido, uno de los referentes hagiográficos que tuvo el siglo XVIII fue San Juan Nepomuceno, canonizado en 1729 y convertido en baluarte de la Contrarreforma por clérigos e intelectuales de espíritu renovador (Sigüenza Martín, 2012: 261-330). El Archipiélago no quedó al margen de dicho fenómeno y sus templos acogieron pronto esculturas del afamado mártir de la confesión, especialmente obras lo- cales, americanas y andaluzas. En estudios previos advertimos que antes de concluir el Setecientos pudieron importarse desde Sevilla varias representaciones de este santo, pues así lo avalan, entre otras, la ya tratada de El Ancón [1] y una que conserva al culto la iglesia de la Concepción en La Orotava, sobre la que volveremos luego [6]. En esta dinámica se inscriben piezas de pequeño formato como la talla del santo de Nepomuk que existe en la parroquia de Los Llanos de Aridane, quizá uno de los "cinco santitos" llegados por indicación del beneficiado Francisco Fierro en febrero de 1760 (Lorenzo Lima, 2018: 16, 26-27, aunque antes se ocupó de ella Amador Marrero, 2005: 11-20), y algunas de mayor tamaño como las figuraciones que conservan los templos de El Salvador en Santa Cruz de La Palma gracias a una donación efectuada por el mismo Fierro, obra de adscripción segura a Hita y Castillo (fue citada como adición en un inventario de 1757, Amador Marrero y Pérez Morera, 2000: 6), o Nuestra Señora de la Concepción en la capital tinerfeña, inventariada ya en 1744 (era tenida como obra de origen italiano por Castro Brunetto, 2004: 38). Igual notoriedad revisten en ese sentido una efigie de la ermita de San Antonio Abad de Las Palmas de Gran Canaria, que ha sido identificada con otra que el clérigo Francisco Antonio de Sosa y Montesdeoca adquirió en Sevilla antes de 1761 y parece creación indudable de Hita (Concepción Rodríguez, 1992: 527-532); y una más pequeña de la parroquia de San Sebastián de La Gomera, cuyo encargo posibilitaron las mandas testamentarias que el clérigo Diego Álvarez Orejón dictó en 1779 (Darias Príncipe, 1986: 75).

A ellas se viene a sumar otra representación notable, exhibida en el tesoro o museo de la iglesia matriz de La Orotava [3]. En un principio, siguiendo apuntes de un registro tardío y erróneo de sus bienes, creímos que esta talla de tamaño medio podía figurar a San Felipe Neri. Sin embargo, dicha hipótesis queda descartada al relacionarla con obras ya referidas y valorar como atributo iconográfico su atuendo con bonete, sotana, sobrepelliz decorada a punta de pincel en los encajes de la parte inferior y muceta que contempla la simulación de armiño al interior. Además, los inventarios del templo no avalan su existencia en él hasta fechas tardías, aunque ello puede deberse a su resguardo en las sacristías altas junto a otras imágenes que manifestaban el mismo deterioro que ha subsanado un reciente proceso de restauración (Rodríguez Padrón, 2015). 
Tal particularidad nos lleva a pensar que sea el «santo antiguo» que unos «fieles de conveniencia» regalaron al párroco Manuel Díaz Llanos en 1934², aunque, desde luego, la pieza arroja una cronología anterior y podría estimarse como un trabajo sevillano del último tercio del Setecientos. Otra posibilidad es que corresponda con la efigie que existió en poder de los Montenegro y el presbítero Juan de Montenegro, ya citado, cedía a su hermano Críspulo Restituto junto a un retrato suyo en abril de 1810 para cumplir «el fin que le tengo indicado ${ }^{13}$, pero de momento ni ese cometido ni su identificación pueden verificarse con apoyatura documental. De ser válida dicha hipótesis, se trataría de una obra destinada al culto privado y confirma la devoción que los miembros de esa familia sintieron hacia San Juan Nepomuceno.

Lo que parece quedar claro es que no presidió el retablo que los Montenegro erigieron al santo en el vecino convento de San Nicolás, porque, como reconoce José de Montenegro en el testamento de 1789, ese altar contuvo una pintura que adornaba ocasionalmente con alhajas de plata. Ordenó a sus herederos que lo cuidaran y asearan, tras ganar la propiedad de una sepultura frente a él que el obispo Antonio Martínez de la Plaza le había concedido meses antes ${ }^{14}$. Un inventario de 1826 confirma que entre los bienes que poseía la iglesia conventual se encontraba todavía «una lámina de San Juan Nepomuceno con su cristal y guarnición dorada» ${ }^{15}$, quizá la misma que José costeó en 1736 y fue trasladada allí con motivo de la reconstrucción de la parroquia en 1768. A ella no volvió tras su apertura al culto años después, por lo que en el templo nuevo sería sustituida por una escultura sevillana que estudiaremos luego [6]. De acuerdo a dicha dinámica, la que nos ocupa ahora fue una pieza destinada al ámbito doméstico o a un espacio de culto menor, todavía sin identificar. Quizá por ese motivo, y a diferencia de lo que sucede con figuraciones análogas de El Ancón, La Orotava y Las Palmas, su representación no se complementa con un angelito que pide silencio a los pies del santo [1].

Relacionada antes con el arte de Duque Cornejo e Hita y Castillo (Rodríguez Padrón, 2015), es obra de calidad y parangonable con efigies ya citadas de la ermita de El Ancón (c. 1770) y de la misma parroquia (c. 1775), por lo que no dudamos al vincular su hechura con Blas Molner. Abundan en ello características comunes como la resolución volumétrica, la disposición de los brazos y del cuerpo en ligero con-

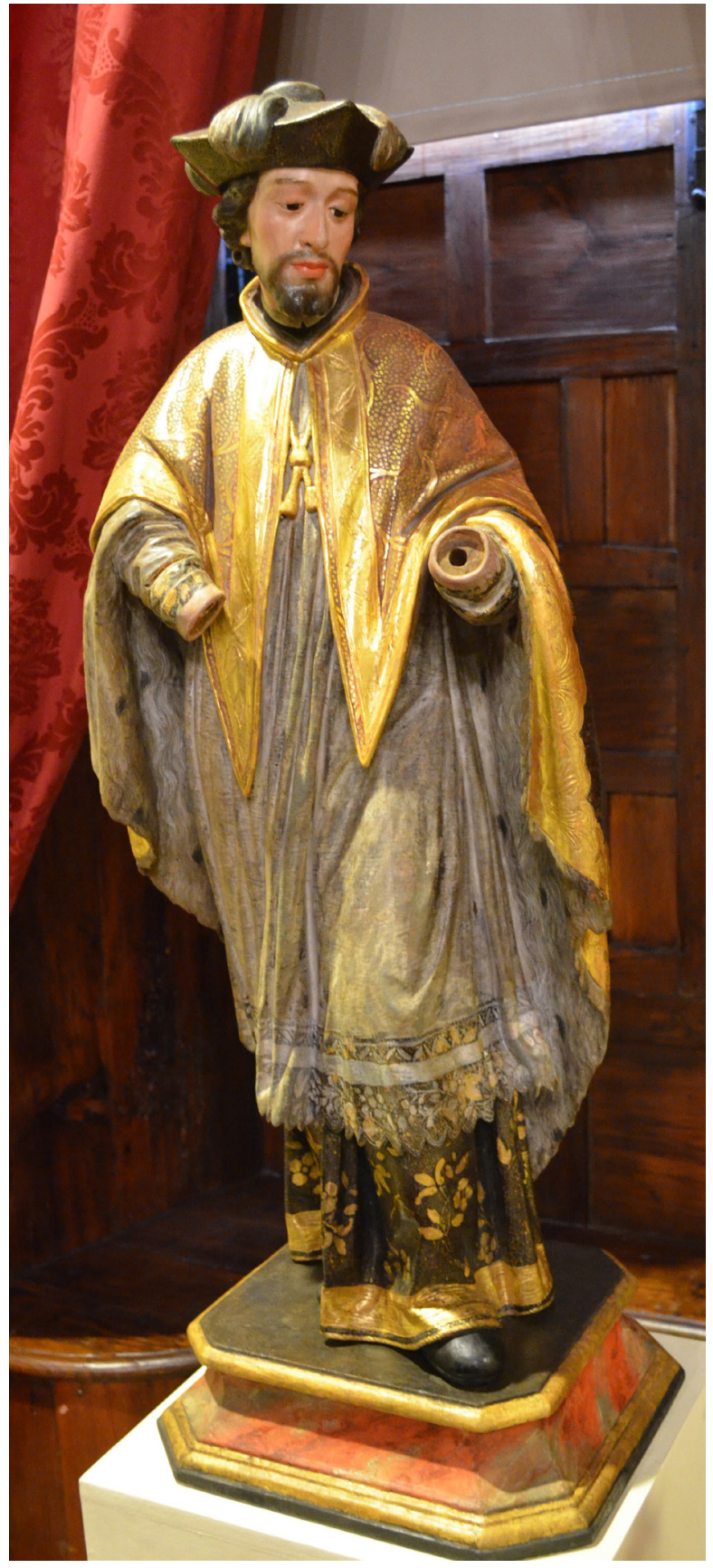

3. Atribuido a Blas Molner, San Juan Nepomuceno Parroquia de Nuestra Señora de la Concepción, La Orotava (foto: Juan Alejandro Lorenzo) 

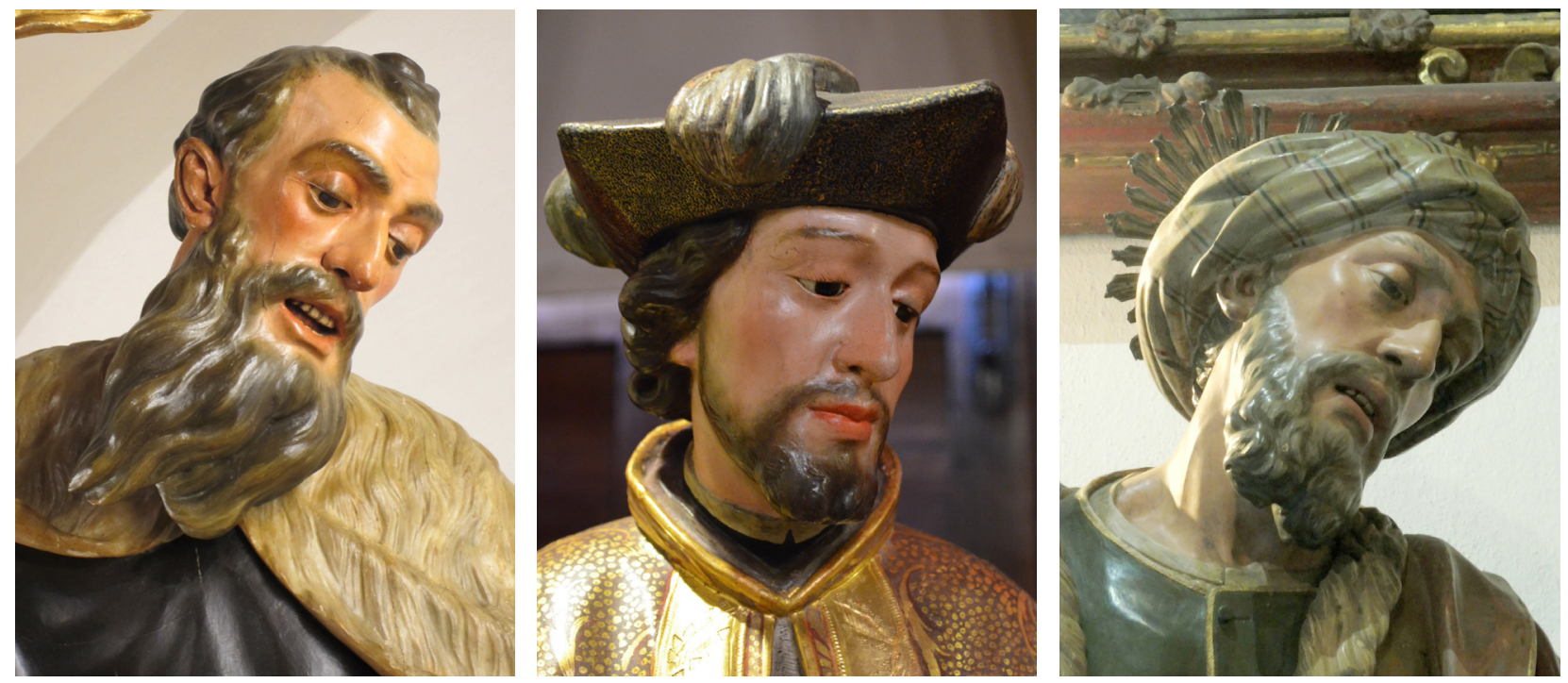

4. Atribuido a Blas Molner, San Elías. San Juan Nepomuceno. San Joaquín (detalles). Iglesia de la Limpia Concepción de Nuestra Señora, Écija. Parroquia de Nuestra Señora de la Concepción, La Orotava. Parroquia de San Andrés, Sevilla (fotos: Juan Alejandro Lorenzo y José Roda Peña)

traposto, el planteamiento iconográfico, la sencillez de las decoraciones estofadas, la configuración de una peana que muestra el marmoleado afín como distintivo y, ante todo, la definición de los rasgos fisonómicos. Los tipos de Molner son reconocibles en esta pieza, pero, como nos advierte Roda Peña, guarda una afinidad mayor con la representación de Elías que conservan los carmelitas de Écija (1791) y con el San Joaquín que integra un grupo junto a Santa Ana y la Virgen Niña en la parroquia sevillana de San Andrés (c. 1785), ambos trabajos notorios del artista [4].

\section{Dos imágenes más para la parroquia matriz de La Orotava}

La escultura sevillana del siglo XVIII -y por consiguiente, la imaginería de un maestro afamado como Molner- no resultaba ajena a los principales comitentes de Canarias, pues obras que le atribuimos ahora guardan relación con edificios de gran notoriedad a finales del Antiguo Régimen. Uno de ellos fue la iglesia de Nuestra Señora de la Concepción en La Orotava, el más importante de cuantos se construyeron entonces en el Archipiélago. Su bendición en diciembre de 1788, tras un complejo proceso de reedificación que duró más de veinte años, puso de relieve la necesidad de acomodar un ornato nuevo y renovar buena parte del patrimonio heredado. Antes de que se produjera su apertura al culto, el mayordomo Domingo Valcárcel y Llarena (1751-1824) procuró que la parroquia estuviese lo mejor dotada posible y cumplir así la tarea que le fue encomendada por varios visitadores y obispos a partir de $1776^{16}$.

La variedad de bienes comprados para ese templo en tan corto periodo de tiempo sorprende aún y, como era habitual desde época precedente, entre ellos no faltaron esculturas andaluzas de buen gusto. En dicho contexto se inscribe la adquisición de sendas representaciones de San Juan Nepomuceno y San Francisco de Borja que exhibe el retablo actual de la Virgen de Candelaria [5] y [6], ensamblado en una capilla de la nave del evangelio cuando mediaba el siglo XIX (Riquelme Pérez, 1990: 154-155). Décadas antes, en otro contexto y bajo circunstancias desconocidas, debió producirse su encargo por indicación de Valcárcel a algún eclesiástico o particular porque su pago no es referido en el libro de fábrica correspondiente ni en otros documentos de la mayordomía. Abunda en esa hipótesis el hecho de que José de Montenegro costeara la fiesta del santo hasta su muerte en 1789 (así lo prueban apuntes incluidos en los libros de entierro de la parroquia, además de algunos recibos 

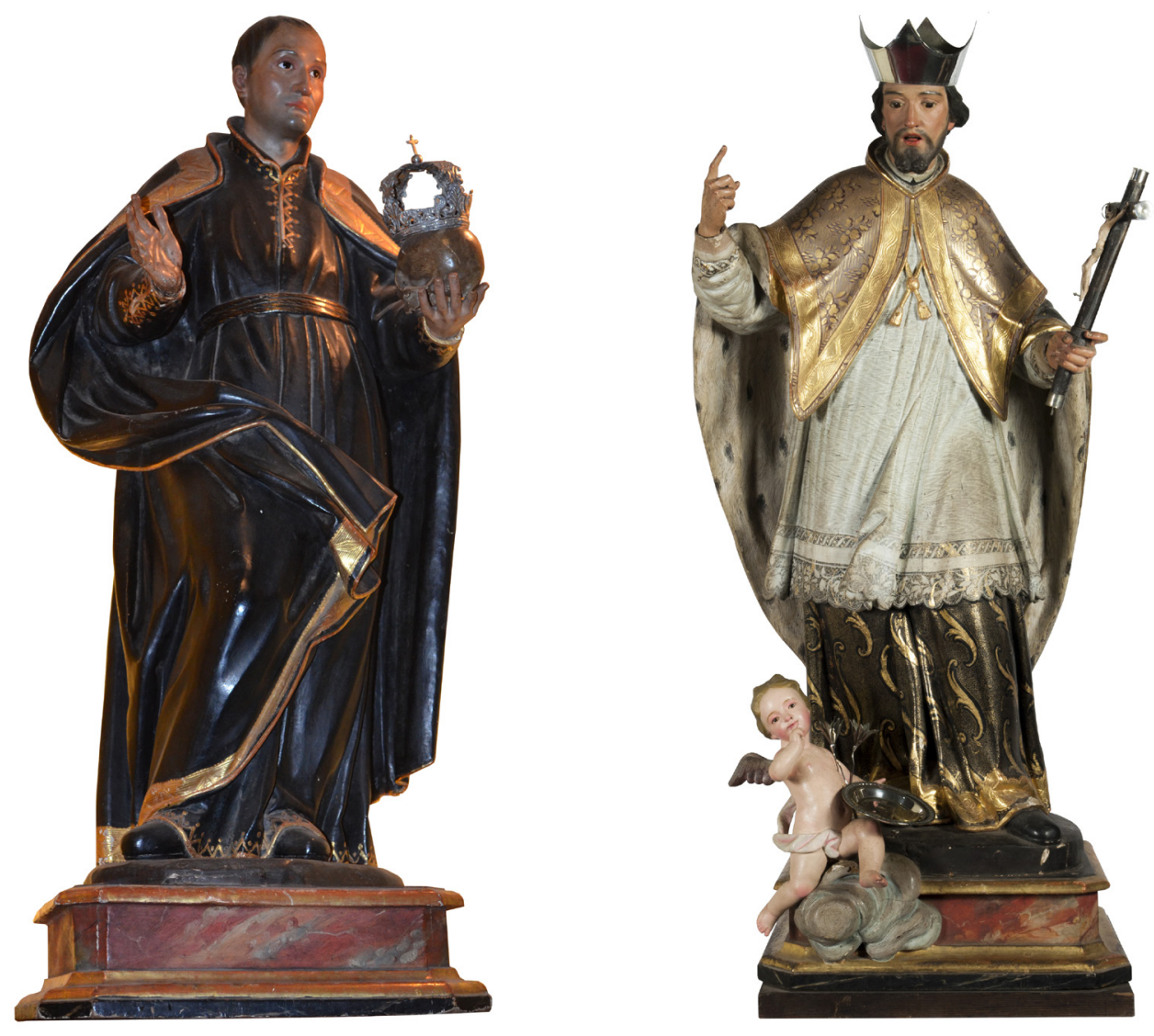

5 y 6. Atribuido a Blas Molner, San Francisco de Borja. San Juan Nepomuceno. Parroquia de Nuestra Señora de la Concepción, La Orotava (fotos: Juan Alejandro Lorenzo y Josué Hernández)

de pago sueltos) o que los clérigos que servían en la parroquia cuidaran luego de la escultura nueva, pues al testar en 1814 Domingo Calzadilla (1751-1816) declaraba haber comprado varias alhajas de plata para adornarla ${ }^{17}$.

Sorprende que de estas efigies se conozca tan poco, pero es indudable que forman parte de un mismo encargo atendiendo a sus dimensiones, el estudio morfológico, la volumetría y, ante todo, el aspecto de unas peanas que muestran igual configuración y apariencia marmórea. En cualquier caso, el dato de mayor antigüedad que disponemos acerca de ellas refiere la autorización concedida en 1776 por el obispo Juan Bautista Servera para que la talla del santo de Borja fuese colocada en un retablo que la cofradía de San Cayetano y San Fernando iba a erigir a sus titulares en la iglesia recién bendecida ${ }^{18}$. Para esas fechas ambas se en- contrarían en La Orotava con el fin de reemplazar a figuraciones previas, sobre todo a la pintura del santo de Nepomuk que, como sabemos, José de Montenegro costeó en 1736 y fue trasladada con un carácter definitivo a la iglesia de monjas dominicas.

Aunque se antoja anecdótica, la noticia es del mayor interés si tenemos en cuenta que el mayordomo de dicha asociación iba a confiar el sobredorado de su altar al pintor Cristóbal Afonso, quien trabajaba ya en la localidad ${ }^{19}$; y con él pudo ajustar también entre 1776 y 1781 el reestofado de la imagen previa del santo rey junto al sobrevestido con telas encoladas, los estofados y la nueva carnación de la de San Cayetano ${ }^{20}$, emulando en la última el ornato de las tallas de San Ignacio de Loyola (1763) y de San Francisco Javier (1764) que eran propiedad del colegio jesuita de la localidad 

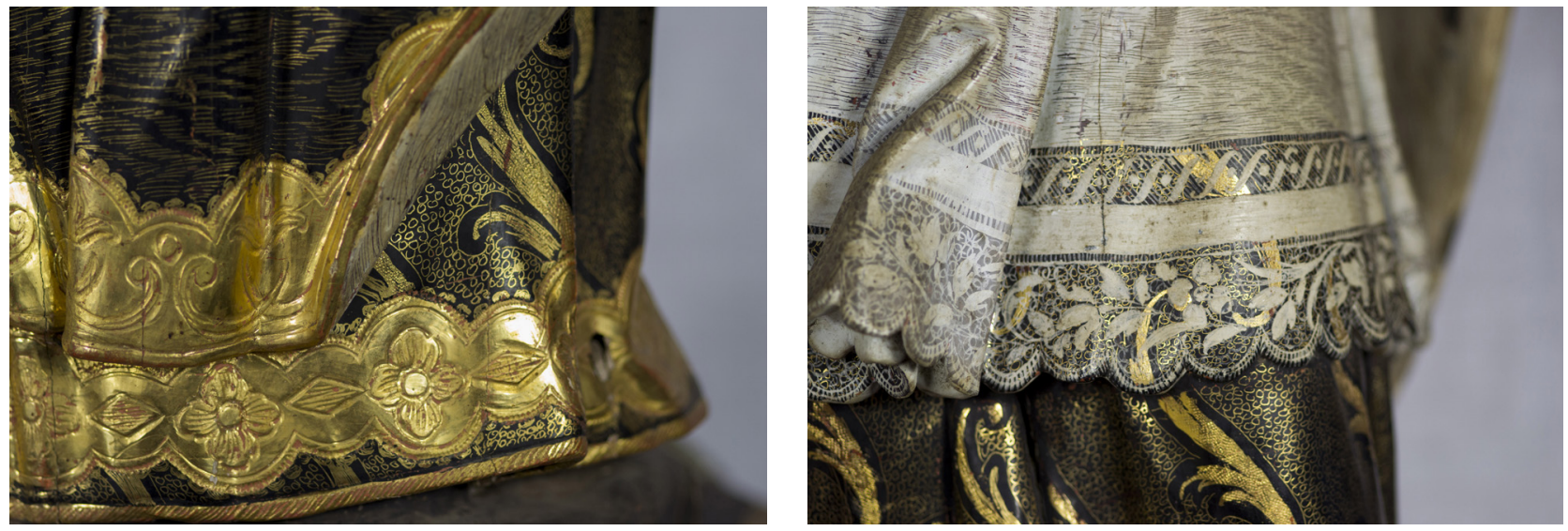

7. Atribuido a Blas Molner, San Juan Nepomuceno (detalles). Parroquia de Nuestra Señora de la Concepción, La Orotava (fotos: Josué Hernández)

y se destinaron a la parroquia tras su cierre en 1767. Lo sugerente es que las últimas son trabajos atribuidos a Benito de Hita y Castillo (Lorenzo Lima, 2006: 154-155), por lo que esas «buenas efigies», muy elogiadas tras su exhibición al público, influyeron en la apariencia procurada a simulacros seiscentistas y tal vez en el encargo de las obras que estudiamos ahora o de otras coetáneas [3]. La adquisición de imágenes sevillanas no cesó entonces, de modo que antes de que concluyera el siglo algunas iglesias de La Orotava incrementaron su patrimonio con tallas andaluzas. Sirva de ejemplo en ese sentido el «medio cuerpo, cabeza y manos de la imagen de Nuestra Señora de los Dolores» que las monjas dominicas pusieron al culto en el templo conventual de San Nicolás, perdido luego y arribado a Tenerife en marzo de 1779 (Fraga González, 1979: 204).

En lo referente a San Francisco de Borja, queda claro que su autor simplificó el modo compositivo impuesto por Pedro Duque Cornejo a otra representación del mismo santo que el oratorio sevillano de San Luis de los Franceses conserva desde 1734 [5]. Tal paralelismo y la resolución del atuendo jesuita con capa recogida en el lado izquierdo motivaron que algunos investigadores vincularan al simulacro tinerfeño con ese imaginero (Rodríguez Bravo, 2015: 202203), pero, como manifestamos en otra ocasión, nos parece de menor calidad, tardío y distante de su estilo (AA W, 2003: 124-126). Lo revelador es que para la concreción de piezas afines maestros dieciochescos copiaron y reinventaban las creaciones de artistas previos, algo que, a su vez, impide formular hipótesis certeras sobre la autoría, el contexto del ajuste, la datación y el grado de originalidad que revelan trabajos coetáneos. Avala este encargo el hecho de que, tras la expulsión de los padres de la Compañía, muchos cultos que se oficiaban en su fundación de la Villa empezaran a servirse en la misma parroquia desde $1767^{21}$.

Mayor interés despierta la efigie complementaria de San Juan Nepomuceno, puesto que su ornato sí reproduce rasgos acordes al gusto imperante [6]. Insisten en ello detalles de la policromía como el marmolado de la base, la recreación cuidada del armiño, el simulacro de brillos con efectos de telas lisas y los estofados de la sotana inferior sobre fondo negro, que simplifican repertorios al uso para obtener mayor naturalidad y armonía visual. La corrección del acabado se hace extensible al atuendo clerical que componen la misma sotana, el roquete y la esclavina sobrepuesta, así como el mimetismo fiel del encaje y de los galones con decoraciones a punta de pincel y estucos en relieve, finamente sobredorados [7]. A falta de pistas documentales, estas cualidades nos inducen a datar ambas piezas durante la década de 1770, aunque sus carnaciones -y particularmente las del angelito de la peana, habitual complemento iconográfico- fueron alteradas a raíz de una intervención acometida por Nicolás Perdigón en 192822.

El acabado del santo de Nepomuk es notorio [8] y, tras un análisis comparativo con piezas coetáneas, defendemos la posibilidad que sea un trabajo más de Blas Molner junto a la talla menos lograda de San Francisco de Borja. Abundan 
en esa posibilidad el estilo de las esculturas, sus volumetrías y la definición de prototipos fácilmente reconocibles, aunque obras de su misma naturaleza caen dentro de unas cualidades que con cierta frecuencia resultan recurrentes y no se prestan a una diferenciación fácil por la reiteración de soluciones poco distintivas en lo morfológico y lo ornamental. Pese a ello, ambas sugieren un encargo que fue premeditado y se produjo en sintonía con imágenes llegadas al Archipiélago antes de 1780, porque el marmoleado de sus peanas es parecido con el que revela la talla homónima de La Gomera y, sobre todo, con el que muestran dos figuraciones de El Ancón, trabajos seguros de Molner [1].

8. Atribuido a Blas Molner, San Juan Nepomuceno (detalle). Parroquia de Nuestra Señora de la Concepción, La Orotava (foto: Josué Hernández)

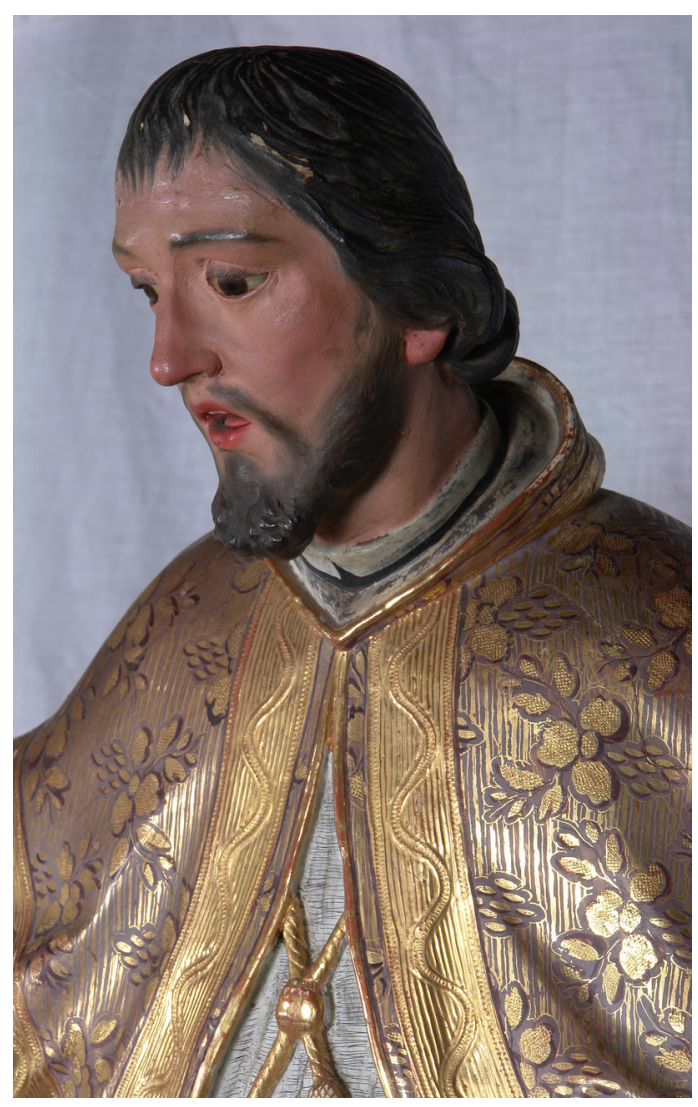

\section{Notas}

1 Este artículo se enmarca en las acciones desarrolladas por el grupo de investigación Arquitectura y desarrollo turístico sostenible (Universidad Europea de Canarias, Tenerife).

2 Son conocidas las cartas de arrendamiento que el artífice suscribió por ese inmueble entre al menos 1766 y 1772 (Prieto Gordillo, 1995: 129-130).

3 Archivo parroquial Nuestra Señora de la Concepción, La Orotava (APCLO): Libro VII de entierros, ff. 614r-614v.

4 AHPT: Protocolos Notariales (PN). Legajo 2894, ff. 239r-239v, 253v-254r.

5 APCLO: Caja «ermitas», expedientes sin clasificar.

6 Ibidem.

7 Aunque la leyenda de la Virgen pudo ser reescrita en 1883, el maestro o quien las policromó por encargo suyo terminaría firmando las tres efigies al frente de la base. Las inscripciones muestran diversa letra y aluden al artista, a su origen valenciano y a la ejecución en Sevilla, no aportando fecha alguna.

8 AHPT: PN. Legajo 2894, f. 236r.

9 AHPT: AZC. Correspondencia. Sign. 545/71-72; 546/15; 551/86; 616/52; 708/15; 720/75; 735/49; 763/45, 73; 769/12, 776/43, 50-53; 779/36, 69; 780/51, 78, 50; 781/09-10, 33-34; 809/92; 818, 14-18; 838/67; 850/41; 891/01-02; 911/09; 920/54; 927/48; 932/21, 28; 944/92.

10 Archivo Familia Perdigón, La Orotava (AFPLO): Diarios manuscritos. D-2, f. 37.

11 Tuvo un coste total de 200 pesetas, sufragado en gran parte por vecinos y devotos de la imagen. AFPLO: Diarios manuscritos. D-1, f. 3.

12 AFPLO: Carpetilla «papeles varios». Notas manuscritas sueltas, sin clasificar.

13 AHPT: PN. Legajo 3094, f. 604r. Cit. Rodríguez Bravo (2015: 203).

14 AHPT: PN. Legajo 2894, ff. 255v-256r.

15 Archivo Histórico Diocesano de La Laguna (AHDLL): Fondo histórico diocesano. Legajo 1485, documento 15, f. 15v.

16 APCO: Libro III de cuentas de fábrica, f. 140r.

17 APCLO: Testamentos. Caja 1, expediente sin clasificar.

18 APCLO: Libro de la cofradía de San Cayetano, f. 53v. 
19 APCLO: Libro de la cofradía..., ff. 65v, 74r (cit. Rodríguez González, 1986: 112).

20 APCLO: Libro de la cofradía..., f. 63r.

21 Entre ellos la misa impuesta al santo de Borja por el deán Bartolomé Benítez de Lugo en 1730, donante de la escultura homónima de Duque Cornejo que subsiste en Las Palmas de Gran Canaria (c. 1732). APCLO: Cuadrante de misas y capellanías (1776), f. 177r.

22 AFPLO: Diarios manuscritos. D-2, f. 20.

\section{Bibliografía}

AA. W. (2003), El Tesoro de la Concepción (catálogo de la exposición homónima), Ayuntamiento de La Orotava, La Orotava.

AA. W. (2007), Luján Pérez y su tiempo (catálogo de la exposición homónima), Gobierno de Canarias, Islas Canarias.

ACOSTA JORDÁN, Silvano (2004), «Tres esculturas de Blas Molner en la ermita de Nuestra Señora de Montenegro», Revista de Historia Canaria, n. ${ }^{\circ} 186$, pp. 9-20.

AMADOR MARRERO, Pablo F. (2005), «El escultor Benito de Hita y Castillo y el San Juan Nepomuceno de Los Llanos de Aridane», Revista de Historia Canaria, n. ${ }^{\circ} 187$, pp. 11-20.

AMADOR MARRERO, Pablo F. y PÉREZ MORERA, Jesús (2000), «El Cristo de la Caída de Santa Cruz (La Palma)», Revista de imaginería, n. ${ }^{\circ} 25$, pp. 3-8.

AMADOR MARRERO, Pablo F. y RODRÍGUEZ MORALES, Carlos (2007), «La plástica canaria del Setecientos. Artistas locales y obras foráneas en el escenario artístico canario», en AA W, Luján Pérez y su tiempo, Gobierno de Canarias, Islas Canarias, pp. $235-267$.

CASTRO BRUNETTO, Carlos (2004), «Escultura barroca en la iglesia de la Concepción de Santa Cruz de Tenerife», Revista de Historia Canaria, n. ${ }^{\circ} 186,21-50$.

CECCHI TONCELLI, Graziella (2001), Un'emigrante d'eccezione: la Madonna di Montenero, Belforte \& C. Editori, Livorno.

CONCEPCIÓN RODRÍGUEZ, José (1992), «Una talla atribuida a Benito de Hita y Castillo en Las Palmas de Gran Canaria», en AAW, Homenaje al profesor Jesús Hernández Perera, Universidad Complutense y Gobierno de Canarias, Madrid, pp. 527-533.

- (1995), Patronazgo artístico de Canarias en el siglo XVIII, Las Palmas de Gran Canaria: Cabildo de Gran Canaria.

DARIAS PRíNCIPE, Alberto (1986), Lugares colombinos de la villa de San Sebastián, Cabildo de La Gomera, Santa Cruz de Tenerife.

ESCUDERO SÁNCHEZ, José María (2009a), «El escultor e imaginero Blas Molner. Nuevas aportaciones a su biografía (I)», Boletín de las cofradías de Sevilla, n. ${ }^{\circ} 600$, pp. 125-129.

- (2009b), «El escultor e imaginero Blas Molner. Nuevas aportaciones a su biografía (y II)», Boletín de las cofradías de Sevilla, n. ${ }^{\circ} 601, \mathrm{pp}$. 201-205

- (2009c), «La obra pasionista de Blas Molner», Boletín de las cofradías de Sevilla, n. 602, pp. 307-316.

FRAGA GONZÁLEZ, María del Carmen (1979), «La aristocracia y la burguesía canarias ante el arte y las importaciones artísticas», Anuario. Centro asociado de Las Palmas UNED, n. ${ }^{\circ}$ 5, pp. 165-217.

- (1998), «La casa comercial Cólogan y las adquisiciones en torno a 1800», en Actas del XIl coloquio de Historia Canario Americana, Cabildo de Gran Canaria, Las Palmas de Gran Canaria, t. II, pp. 203-218.

HERRERA GARCÍA, Francisco Javier (2009), «Virgen de Candelaria», en AA W, Vestida de sol. Iconografía y memoria de Nuestra Señora de Candelaria (catálogo de la exposición homónima), Fundación CajaCanarias, La Laguna, pp. 178-179.

- (2014), «Escultura sevillana de la segunda mitad del siglo XVIII: prejuicios, ideas teóricas y algunas atribuciones», Archivo Hispalense, n. ${ }^{\circ}$ 294-296, pp. 269-293.

LORENZO LIMA, Juan Alejandro (2006), «San Francisco Javier», en AA W, Roque de Montpellier. Iconografía de los santos protectores de la peste en Canarias (catálogo de la exposición homónima), Ayuntamiento de Garachico y Gobierno de Canarias, Garachico, pp. 154-155.

- (2016), "Otro episodio de comercio artístico. Esculturas andaluzas en Tenerife a principios del siglo XIX», Laboratorio de Arte, n. ${ }^{\circ} 28$, pp. 401-431. 
LORENZO LIMA, Juan Alejandro (2018), «Arte y comercio a finales de la época Moderna. Notas para un estudio de la escultura sevillana en Canarias (1770-1800)", Anuario de Estudios Atlánticos, n. ${ }^{\circ}$ 64, pp. 1-57.

LUQUE HERNÁNDEZ, Antonio (2004), «El libro verde de los Montenegro tinerfeños», Hidalguía: revista de genealogía, nobleza y armas, n. ${ }^{\circ}$ 303, pp. 241-254.

OBERHAUSEN, Giorgio (1745), Istoria della miracolosa immagine di Nostra Signora di Montenero, Sebastiano ed Angelo Cappuri, Lucca. PADRÓN RODRÍGUEZ, Adolfo (2015), Del silencio a la recuperación. Estudio histórico y conservación-restauración de la imagen de San Juan Nepomuceno de la parroquia de la Concepción de La Orotava (trabajo fin de grado, inédito), Universidad de La Laguna, La Laguna.

PÉREZ MORERA, Jesús (2015), «El comercio artístico entre Sevilla y Canarias a través del tratante García de Azcárate y el escultor Hita del Castillo», Atrio: revista de Historia del Arte, n. ${ }^{\circ} 21$, pp. 88-107.

PRIETO GORDILLO, Juan (1995), Noticias de escultura (1761-1780) (Fuentes para la historia del arte andaluz, t. XV), Ediciones Guadalquivir, Sevilla.

RECIO MIR, Álvaro (2000a), «La pugna entre académicos y gremios: Molner y los Cano», Academia, n. 91, pp. 41-50.

- (2000b), «El final del barroco sevillano: Manuel Barrera y Carmona, Blas Molner y el retablo mayor de San Bernardo», Archivo Hispalense, n. ${ }^{\circ} 252$, pp. $129-147$

- (2007), «La escultura sevillana, la Academia de San Fernando y el ocaso de la escuela», Academia, n. ${ }^{\circ}$ 104-105, pp. 133-156.

RIQUELME PÉREZ, María Jesús (1990), La Virgen de Candelaria y las Islas Canarias, ACT, Santa Cruz de Tenerife.

RODA PEÑA, Jesús (1993), «A propósito de una escultura dieciochesca de San José», Laboratorio de Arte, n. ${ }^{\circ}$ 5, pp. 369 -378.

- (2014), «La escultura barroca del siglo XVIII en Andalucía Occidental», Cuadernos de Estepa, n. 4, pp. 84-111.

RODRÍGUEZ BRAVO, Jesús (2015), «Arte y perpetuidad: José de Montenegro y la capilla de Ánimas del convento de San Benito de La Orotava", Revista de Historia Canaria, n. ${ }^{\circ} 197$, pp. 199-241.

RODRíGUEZ GONZÁLEZ, Margarita (1986), La pintura en Canarias durante el siglo XVIII, Cabildo de Gran Canaria, Las Palmas de Gran Canaria.

RODRÍGUEZ MORALES, Carlos (2010), «Presencia e influencia de la escultura andaluza en Canarias», en GILA MEDINA, Lázaro (coord.), La escultura del primer naturalismo en Andalucía e Hispanoamérica (1580-1625), Arco Libros, Madrid, pp. 457-472.

ROS GONZÁLEZ, Francisco Sabas (1999), Noticias de escultura (1781-1800) (Fuentes para la historia del arte andaluz, t. XIX), Ediciones Guadalquivir, Sevilla.

- (2009), «Competencia e intrusismo profesional en el medio artístico sevillano del Neoclasicismo». En GONZÁLEZ GÓMEZ, Juan Miguel y MEJÍAS ÁLVAREZ, María Jesús (eds.), Estudios de historia del arte. Centenario del Laboratorio de Arte (1907-2007), Universidad de Sevilla, Sevilla, t. II, pp. 307-316.

SIGÜENZA MARTíN, Raquel (2012), «La iconografía de San Juan Nepomuceno y su repercusión en España», Cuadernos de arte e iconografía, n. ${ }^{\circ} 42$, pp. $261-330$. 
